\title{
Accreditation of Medical Laboratories in Europe: Statutory Framework, Current Situation and Perspectives
}

\author{
Folker Spitzenberger Rainer Edelhäuser \\ Zentralstelle der Länder für Gesundheitsschutz bei Arzneimitteln und Medizinprodukten, Bonn, Germany
}

\section{Key Words}

New Approach · Accreditation · Quality management . IVD · EN ISO 15189

\section{Summary}

Due to economic and technological changes in laboratory medicine that go along with new regulatory requirements in the field of medical devices, the implementation of quality systems in medical laboratories has broadly expanded within Europe during the last decade. In the context of the New Approach, the competence of medical laboratories is of decisive importance for premarket conformity assessment of medical devices including in vitro diagnostics and should be confirmed by accreditation. Although EN ISO/IEC 17025 and EN ISO 15189 provide useful requirements for laboratory testing, these standards are insufficient for giving full presumption of conformity in connection with requirements set by European directives. Additional regulatory documents and standards as the CTS and EN 13612 should be considered. Although accreditation in most European countries is voluntary, the requirement for implementation of quality management systems in medical laboratories has been introduced into the national legislation of many Central and Western European countries. Along with this development, accreditation according to EN ISO/IEC 17025 and, since 2003 according to EN ISO 15189, constitutes the main external quality assessment procedure for medical laboratories. Perspectives for accreditation will mainly be influenced by the currently performed changes of the medical devices directive 93/42/EEC and the review of the New Approach.

\section{Schlüsselwörter}

New Approach · Akkreditierung · Qualitätsmanagement . IVD · EN ISO 15189

\section{Zusammenfassung}

Aufgrund ökonomischer und technologischer Veränderungen in der Labormedizin sowie neuer regulatorischer Anforderungen im Medizinproduktebereich hat die Einführung von Qualitätsmanagementsystemen in medizinischen Laboratorien in den letzten Jahren zunehmende Bedeutung in Europa erlangt. Im Zusammenhang mit der Neuen Konzeption (New Approach) europarechtlicher Bestimmungen spielt die Kompetenz medizinischer Laboratorien bei der Konformitätsbewertung von Medizinprodukten einschließlich In-vitro-Diagnostika eine zentrale Rolle. Die Bestätigung der Kompetenz sollte daher durch Akkreditierung erfolgen. Zwar enthalten die Normen EN ISO/IEC 17025 und EN ISO 15189 relevante Prüfbzw. Untersuchungskriterien, aber sie entfalten keine vollständige Konformitätsvermutung im Hinblick auf die in den europäischen Richtlinien dargelegten Anforderungen. Aus diesem Grund müssen für die Akkreditierung weitere Spezifikationen und Normen wie die GTS und EN 13612 berücksichtigt werden. Obwohl die Akkreditierung in den meisten Ländern Europas bisher freiwillig ist, wurde die Einführung von Qualitätsmanagementsystemen in medizinischen Laboratorien mittels nationaler Gesetzgebung in vielen mittel- und westeuropäischen Ländern vorgesehen. Die Akkreditierung auf der Grundlage von EN ISO/IEC 17025 und seit 2003 auf der Grundlage von EN ISO 15189 stellt daher mittlerweile das wichtigste Verfahren zur externen Qualitätsüberprüfung medizinischer Laboratorien dar. Zukünftig können durch die Revision der Richtlinie 93/42/EWG über Medizinprodukte und der Regelungen der Neuen Konzeption weitere Konsequenzen für die Akkreditierung erwartet werden.

\begin{tabular}{ll}
\hline KARGER & @ 2006 S. Karger GmbH, Freiburg \\
$\begin{array}{l}\text { Fax +4976145207 14 } \\
\begin{array}{l}\text { E-mail Information@Karger.de } \\
\text { www.karger.com }\end{array}\end{array}$ & $\begin{array}{l}\text { Accessible online at: } \\
\text { www.karger.com/tmh }\end{array}$
\end{tabular}




\section{Introduction}

Medical laboratory services are essential for human healthcare because decisions on diagnosis, treatment, and prognosis are often based on the results and interpretations of medical laboratory tests. In order to assure and improve the level of patient care while limiting the related costs at the same time, the implementation of quality systems in medical laboratories has broadly expanded within all European countries during the last decade.

The quality revolution in medical laboratories goes along with simultaneous innovations of the European legislation in the field of medical devices including in vitro diagnostics (IVD). Since December 2003, any IVD are placed on the European market according to the new requirements of the Directive 98/79/EC on in vitro diagnostic medical devices (IVDD) [1] In consequence, a technical documentation for each IVD is required that - among others - must include a documentation of the quality system established by the manufacturer, the IVD performance evaluation data, and the results of the risk analysis for the device. In this context, medical laboratories that provide the necessary clinical environment to evaluate device characteristics play an important role in the pre-market performance evaluation of IVD. As IVD users, these laboratories are also among the main medical practitioners that contribute to the post-marketing monitoring of IVD.

Since the testing competence of medical laboratories therefore constitutes a decisive precondition for both the highquality performance of analytical procedures and the manufacturing of high-quality products used for in vitro diagnosis, it should be ensured by the implementation of quality management systems. This may be confirmed by laboratory accreditation.

\section{Conformity Assessment in the European Union: New Approach and Global Concept}

The regulation of medical devices including IVD within the European Union (EU) is based on a regulatory strategy called the New Approach originally laid down by a Council Resolution of the year 1985 and presenting a formerly new concept of legal harmonization for a variety of products [2].

This approach was implemented for the accelerated realization of the free movement of goods as a cornerstone of the single market within the EU and is based on the following principles (fig. 1): Firstly, assuming that relevant regulations in the Member States for many products are largely equivalent and that reciprocal recognition of the national regulations would therefore suffice in principle, European legislative harmonization is limited to essential requirements that products placed on the community market must meet in observance of health and environmental protection requirements. Secondly, the technical specifications and manufactur- ing processes meeting the essential requirements set out in the European directives are laid down in harmonized standards. Although these standards are not legislative in nature and their application therefore remains voluntary, the compliance with harmonized standards benefits from a presumption of conformity with the corresponding essential requirements. Thirdly, the New Approach is based on the reciprocal recognition of conformity assessments generally carried out in the responsibility of the manufacturer and supported by competent testing bodies like certification bodies and laboratories that are involved in those cases where product failure can cause serious risks to public health. The conformity assessment procedures result in certificates of conformity accepted by all Member States. Finally, the $\mathrm{CE}$ marking $(\mathrm{CE}=\mathrm{fr}$. 'conformité européenne') of a product indicates the conformity with European legal requirements.

The New Approach was supplemented by the Global Concept that implemented a harmonized, modular concept of product conformity assessment [3-5]. According to this approach, a manufacturer can choose among different conformity assessment procedures that are composed by different modules for the design and the production phase of the product. The New Approach directives provide the information which modules may principally be applied for conformity assessment of the respective products.

\section{The European Medical Devices System and the Role of Medical Laboratories in Medical Device Conformity Assessment}

New Approach and Global Concept are based upon conformity assessment at two levels. The first level is the examination of products, services and processes with regard to their compliance with the requirements of the EU directives, and where applicable, of harmonized standards; for products as for example a medical device, the visible result of this conformity assessment is the CE mark.

Since the quality of these products and therefore also the standard of safety and public health protection, however, directly depend on the quality of the bodies examining the products in the pre-market phase, the Global Concept introduced examination at a second level: conformity assessment of the testing bodies by installation of national accreditation systems to provide confidence in the quality and competence of the testing bodies. In other words, testing bodies acting as conformity assessment bodies are themselves subject to conformity assessment by accreditation procedures performed by accreditation bodies.

In the field of medical devices, certification bodies and testing laboratories act as conformity assessment bodies. In general, the extent of testing and conformity assessment performed by certification bodies increases with the potential risk that is related to the use of the medical device in question. 
Fig. 1. The regulation of medical devices including IVD is based on a regulatory strategy called the New Approach supplemented by the Global Concept.

\section{New Approach and Global Concept: Basic principles}

Harmonization of legislation:

- Only minimum requirements for products in EU-legislation

- Technical specifications in harmonized mandated standards

- Application of standards is voluntary

- Application of standards accounts for „presumption of conformity“ with essential requirements

- Manufacturer has sole responsibility for the conformity of the product

- Harmonized, modular approach for conformity assessment procedures leading to CE-marking

- Minimum requirements also for the activity of conformity assessment bodies (certification and testing bodies)

- Designation and accreditation by national control bodies

IIL Confidence in the quality and competence

II Reciprocal recognition of conformity assessment results
The basic European medical device law is constituted by the Directive 90/385/EEC relating to active implantable medical devices [6], the Directive 93/42/EEC concerning medical devices [7] and the IVDD relating to IVD [1] (fig. 2). The variety of medical device products regulated by New Approach directives therefore comprises, for example, heart valves, catheters, eye lenses, condoms and, as IVD, laboratory systems, test reagents and others.

The certification bodies must comply with the criteria set in certain annexes of the EU directives, for example in Annex IX of the IVDD [1]. These criteria refer to the impartiality of the bodies and their inspection staff, the material and human resources including the scientific and technical competence of the bodies, the professional secrecy, and liability aspects. In most European Member States, the compliance of the certification bodies is assessed and confirmed by accreditation. The following designation of the bodies is performed in the responsibility of the Member States to ensure the compliance of the bodies with the legal requirements. Following the accreditation and designation procedure, the Member States inform the European Commission and the other Member States of the designation of these bodies. Since this procedure is called 'notification', the bodies are also called 'notified bodies'. Subcontractors of notified bodies, for example testing laboratories, must also fully comply with the criteria set in the directives. Their compliance may be confirmed by accreditation [4, $5,8]$. However, subcontractors are not notified to the Commission. According to the New Approach principles, accreditation is valid all over Europe: Any of the accredited testing bodies may be selected by manufacturers in the whole EU for performance of conformity assessments.
In the context of the European medical device system, medical laboratories constitute a special type of testing laboratories that are both directly and indirectly involved in conformity assessment of medical devices. As subcontractors of notified bodies, medical laboratories are involved in the design and type examination of IVD. For the 'verification of manufactured products' usually known as batch testing and required for high-risk IVD covered by Annex II, List A, IVDD (including reagents for the determination of HIV, HTLV, Hepatitis B, C, D and several systems for determining blood groups), medical laboratories are also subcontracted by notified bodies. However, the large majority of medical laboratories involved in pre-market IVD conformity assessment in practice are often not directly contracted by notified bodies. Nevertheless, these bodies significantly rely on laboratory data during their conformity assessments [9] since the results from pre-market IVD performance evaluation obtained by medical laboratories are among the key data for the technical documentation of the devices. Furthermore, clinical laboratory testing also provides data used for conformity assessment of other medical devices than IVD, for example in the context of clinical studies for implantables (fig. 3).

Apart from accreditation in the context of pre-market medical device conformity assessment, medical laboratories are subject to the introduction of quality management systems in connection with the use and application of CE-marked IVD in routine diagnosis. The current development is also a consequence of IVDD provisions and their transformation into national laws of the Member States. The requirements for competence and training of medical and technical professionals in medical laboratories is complementary to the general concept 
of conformity assessment required for IVD. For example, recital No. 22 of the directive points out that 'conformity assessment procedures for IVD are generally carried out under the sole responsibility of the manufacturer' (apart from the limited number of IVD covered by Annex II, IVDD, and home-use tests) because the 'majority of products are not supposed to constitute direct risks to patients and are used by competently trained professionals' [1]. The extent of involvement of third parties in conformity assessment of IVD is therefore lower than for the majority of medical devices regulated by the directives $90 / 385 / \mathrm{EEC}$ or $93 / 42 / \mathrm{EEC}$ where all products or the majority of device classes are subject to conformity assessment by notified bodies, respectively [6, 7]. The complementary implementation of quality management systems by IVD users shall ensure that health and safety requirements are nevertheless observed.

\section{Accreditation and Normative Requirements: European and International Standardization}

Standardization plays a central role in the concept of the New Approach. Compliance with the requirements of harmonized standards benefits from a presumption of conformity with the corresponding essential requirements laid down in European directives [10].

For the elaboration of harmonized standards, the Commission formally requests the European standards organizations CEN $(\mathrm{CEN}=f r$. Comité Européen de normalisation) and/or CENELEC (CENELEC $=f r$. Comité Européen de Normalisation Electrotechnique) to present European standards by issuing a mandate. The standards organizations will formally take a position on the mandate and work out the standards on the basis of a series of principles and commitments concerning standardization, for example the participation of all interested parties, the role of public authorities, the quality of standards and so on. During the late 1980s and 1990s, the presumption of conformity related to requirements for conformity assessment bodies concerned harmonized standards in the EN 45000 series. The standards as originally drafted have since been revised several times; most of them are no longer in force.

This is also true for the standard EN 45001 that was originally published in 1989 and that set 'general criteria for the operation of testing laboratories' [11]. In most European countries, this standard was originally used by national accreditation systems to constitute the basic accreditation criteria for medical laboratories. However, interpretative guides were developed by the national accreditation bodies to meet the special needs and characteristics of medical laboratories [12, 13]. These mainly addressed the medical laboratories' peculiarities to deal with samples of human origin when performing examinations. As almost all standards of the 45000 series, EN 45001 was drafted by CASCO (the committee of the International

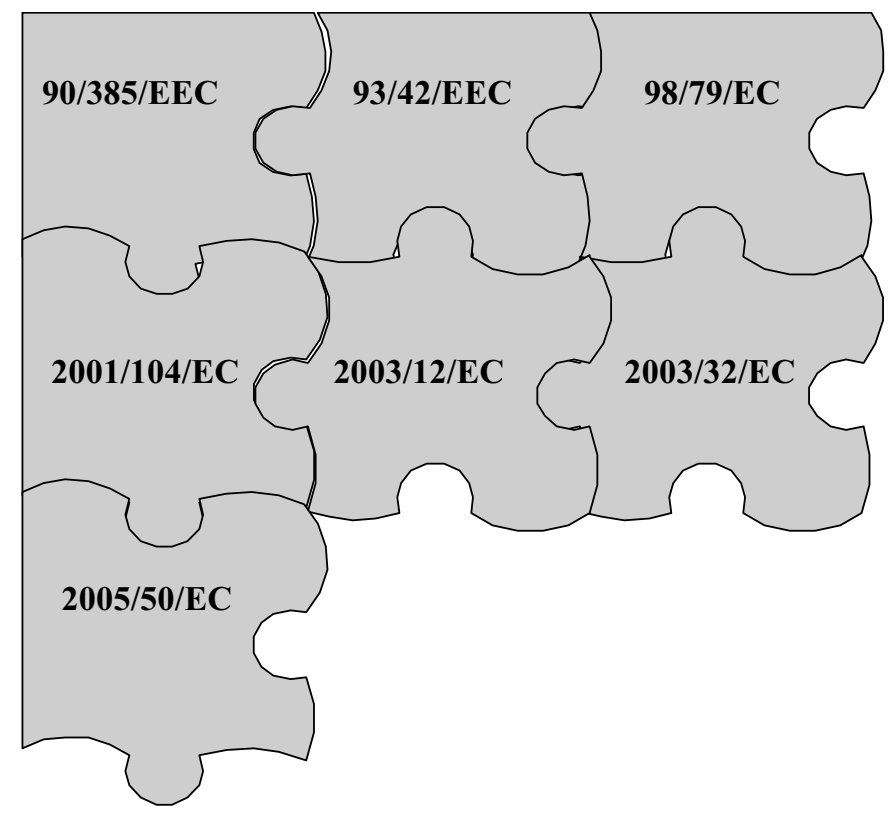

Fig. 2. The European medical device law is constituted by the three basic directives 90/385/EEC, 93/42/EEC and 98/79/EC. These were so far amended by the directives 2001/104/EC on medical devices containing stable derivatives from blood and plasma, 2003/12/EC on reclassification of breast implantables, 2003/32/EC concerning tissues of animal origin and 2005/50/EC on joint replacements.

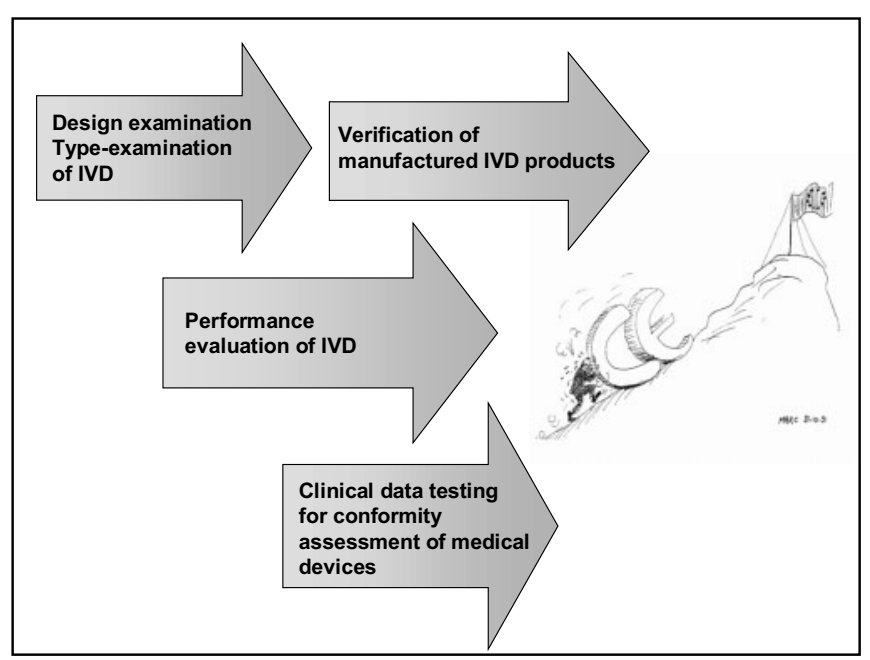

Fig. 3. The role of medical laboratories in conformity assessment of medical devices and IVD. Medical laboratories are involved in pre-market performance evaluation and clinical studies both contracted by manufacturers and subcontracted by notified bodies.

Organisation for Standardization (ISO) that is responsible for conformity assessment) and subsequently adopted by CEN/ CENELEC as EN standard.

Later, the decision has been taken to draft any standards governing conformity assessment bodies and accreditation bodies exclusively by ISO/CASCO and within the ISO/IEC 17000 se- 
ries to have uniform international requirements for these bodies. The standards are adopted in accordance with the $1991 \mathrm{Vi}$ enna Agreement in parallel voting by ISO and CEN members [14].

On the one hand, this has major benefits for worldwide recognition of the results of these bodies, and thus for world trade as a whole, especially in the area which is not subject to statutory regulation. For example, reciprocal agreements between accreditation bodies exist at regional or international level in the form of multilateral agreements (MLAs) that are based on compliance with standards [10]. The purpose of these agreements is the avoidance of multiple conformity assessments of the same subject by reciprocal recognition of conformity assessment results. In Europe, the accreditation bodies have united to form the European co-operation for Accreditation (EA) in order to conclude MLAs. At the international level, the accreditation bodies have set up two organizations which also organize MLAs: IAF (International Accreditation Forum) in the sphere of accreditation of certification bodies, and ILAC (International Laboratory Accreditation Cooperation) in the sphere of accreditation of testing and calibration laboratories.

On the other hand, application of the standards of the 17000 series within the New Approach should imply the consideration of the specific requirements provided by European legislation in these standards. However, as recently shown, a comparison of the standards with the provisions of the EU New Approach directives demonstrates that not all standards cover all requirements of the directives [15]. In particular, deficiencies of the standards refer to aspects like the impartiality, independence and liability of conformity assessment bodies. Therefore, a considerable number of standards used in the context of conformity assessment cannot be regarded as giving rise to the presumption of conformity in the context of the New Approach directives. This is also the case for the standard EN ISO/IEC 17025 [16] that replaced EN 45001 and is used for accreditation of medical laboratories since the year 2000.

Along with the publication of the standards of the 17000 series, the terminology of accreditation (and of other terms like, for example, designation) has very recently been subject to variations. According to EN 45001, accreditation was formerly defined as 'formal recognition that a testing laboratory is competent to carry out specific tests or specific types of tests'. EN 45003 that has now been replaced by EN ISO/IEC 17011 [17] defined accreditation as the "procedure by which an authoritative body gives formal recognition that a body or person is competent to carry out specific tasks'. Furthermore, the recognition of testing laboratory results for conformity assessment procedures performed by certification bodies was noted separately in this standard. In comparison, EN ISO/IEC 17011 and EN ISO/IEC 17000 [18] define accreditation as 'third party attestation related to a conformity assessment body conveying formal demonstration of its competence to carry out specific conformity assessment tasks'. A conformity assessment body is a 'body that performs conformity assessment services and that can be the object of accreditation'. And conformity assessment is defined as the 'demonstration that specified requirements relating to a product, process, system, person or body are fulfilled'.

Consequently, the term 'accreditation' is currently more generally referring to the confirmation of competence for all types of conformity assessment and, furthermore, applicable only to attestation regarding a conformity assessment body and not regarding the certification of persons. However, as recently shown, the definitions and especially applications for the term 'accreditation' as also for the terms 'designation' and 'notification' including the associated procedures are not yet fully harmonized within the EU [15].

Apart from the New Approach provisions, accreditation of testing laboratories in the area not subject to statutory regulation was originally performed according to ISO Guide 25 [19] that for long set the criteria for the assessment of the competence of testing laboratories. As it was and is the case for EN 45001 or EN ISO/IEC 17025, this guide mainly constituted a technically orientated document that did not consider the specific requirements necessary for medical laboratory testing. In 1997, by cooperation of the European Confederation of Laboratory Medicine (ECLM) and EA, an additional guide, EALGuide 25, was therefore published that contained a specific interpretation of ISO Guide 25 for medical laboratories [20]. Since 1995, the technical committees ISO/TC212 'Clinical laboratory testing and in vitro diagnostic test systems' and CEN/TEC 140 'In vitro diagnostics' prepared a standard, based upon ISO/IEC 17025 and ISO 9001 [21], which provided requirements for the competence and quality that are particular to medical laboratories. It was finally published by ISO in January 2003 and adopted as European standard in the same month as EN ISO 15189 [22]. Although closely related to EN ISO/IEC 17025, as far as the standard structure and content are concerned, EN ISO 15189 recognizes the importance of the specific pre-analytical, analytical and post-analytical requirements for medical laboratories. Here, EN ISO 15189 is largely build upon the 'EC4 Essential Criteria for quality systems of medical laboratories' [23, 24]. Since 2003, EN ISO 15189 represents the main normative basis for the accreditation of medical laboratories.

\section{Implementation of Quality Management Systems in Medical Laboratories}

\section{Accreditation in the Area Subject to Statutory Regulation}

Testing laboratories play an essential role as conformity assessment bodies involved in pre-market testing and evaluation of medical devices. The majority of these laboratories are medical laboratories that provide the necessary clinical envi- 
ronment to perform clinical testing and evaluation of medical devices and IVD by testing samples in the broad range of biovariability. Since these laboratories are either directly subcontracted by notified bodies or - as in most cases - are involved in clinical and performance evaluation studies initiated by manufacturers, they must comply with the criteria set in the EU directives for the designation of notified bodies [5, 9, 25]. These criteria refer to a) the impartiality and independence of the laboratory organization, as far as its relationship to production, distribution, maintenance of medical devices is concerned, b) the scientific, medical and technical competence of the laboratory staff, c) the independence and impartiality of the laboratory staff as individuals, d) the availability of sufficient technical resources for the testing and examination procedures, e) the existence of civil liability insurance, and f) the professional secrecy of the staff. A considerable number of these criteria may be fulfilled by the implementation of quality management systems with subsequent accreditation according to EN ISO 15189 and EN ISO/IEC 17025.

Important to note, although accreditation is recognized by the European Commission as a useful tool for the confirmation of laboratory competence, it is not sufficient without an assessment of all the criteria required by the European New Approach directives [5]. Furthermore, laboratory accreditation is usually performed on a voluntary basis, whereas compliance with the criteria set in the EU directives is mandatory $[1,6,7]$. For example, a laboratory would not possibly fit the criteria if the legal unit, the laboratory belongs to, is involved in development processes, production or distribution of medical devices although the medical competence of the laboratory might be excellent. And - to illustrate another example - if the staff resources are not sufficient to comply with the requirements necessary for performing adequate analysis, which could be the case for laboratory companionships or doctor's practices without scientific staff specifically qualified in laboratory diagnostics, the criteria will neither be fulfilled although testing instruments might be adequate.

The competence of medical laboratories as testing bodies involved in performance evaluation studies for pre-market conformity assessment of IVD is particularly addressed by the IVDD and related specifications. Since performance evaluation data should originate from studies in a clinical or other appropriate environment (if they do not result from relevant biographical references) and a 'device for performance evaluation' means 'any device intended by the manufacturer to be subject to ... performance evaluation studies in laboratories for medical analyses ... outside his own premises' (Article 1, paragraph 2e, IVDD), medical laboratories provide key data for pre-market IVD evaluation and characterization. It should be stressed that performance evaluation studies solely performed inside the manufacturer's premises are thus not acceptable in the view of European legislation - a fact which is sometimes not adequately considered [26].

By IVDD adoption, a new kind of 'standard' was introduced

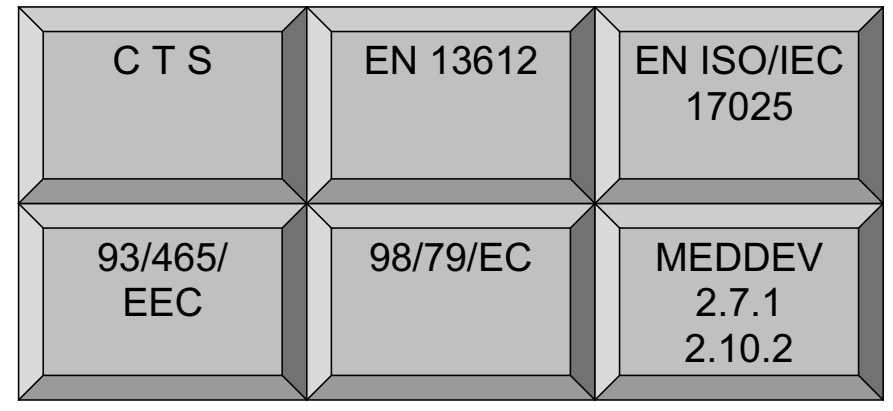

Fig. 4. Basic documents setting the requirements for competence of medical laboratories involved in IVD performance evaluation studies. According to the Council Decision 93/465/EEC, subcontractors of notified bodies must comply with the directive criteria. Apart from EN ISO/IEC 17025, requirements and relevant aspects for laboratories involved in premarket IVD performance evaluation are described in the CTS, a number of MEDDEV documents and EN 13612.

as so called 'common technical specifications' (CTS) [27]. The CTS comprise performance evaluation and re-evaluation criteria, batch release criteria, reference methods, and reference materials for Annex II, List A devices. When applied by the manufacturer, the CTS give presumption of conformity with the essential requirements of the directive. In terms of their binding force, the CTS are superior to harmonized standards but inferior to the directive. When involved in conformity assessment of List A devices, medical laboratories must recognize the significance of these specifications during their reevaluation of the manufacturer's data. A considerable number of requirements for medical laboratories may also be derived from the standard EN 13612 that specifies responsibilities for the conduct, assessment and documentation of performance evaluation studies in general [28].

Laboratory accreditation systems in the area subject to statutory regulation should therefore adequately consider these specific requirements for performance evaluation testing (fig. 4). For these reasons, laboratory accreditation in the field of IVD is in Germany performed by the designating authority Zentralstelle der Länder für Gesundheitschutz bei Arzneimitteln und Medizinprodukten (ZLG). Founded in 1994 along with the national implementation of European medical device law, this institution has the legal and exclusive mandate to perform accreditation in Germany in the area subject to statutory regulation. Accreditation rules for laboratories shall here ensure the compliance with legislative and normative requirements that are beyond the basic laboratory standards EN ISO/IEC 17025 or EN ISO 15189 [1, 28-30]. In a number of other European countries, laboratory accreditation is under governmental control, as, for example, in Austria [31] and Switzerland [32]. In general, however, the implementation of accreditation systems among the Member States in this area is heterogeneous and often does not consider the specific requirements derived from IVD legislation. 
In conclusion, accreditation in the area subject to statutory regulation involves both the implementation of quality management systems according to the current standards for medical laboratories and the compliance with further requirements set by European legislation and harmonized standardization.

\section{Quality Management Systems in the Context of Routine Diagnosis: Accreditation, Certification and Other Quality Assurance Programs}

Apart from the context of conformity assessment of medical devices, the implementation of quality management and quality assurance systems in European clinical laboratories started during the mid-1990s, mainly in the context of the evolution of healthcare systems and technological progress in laboratory medicine.

The developing interest in quality monitoring of laboratory testing in recent years has been driven by the need of cost reduction, changes in reimbursement of laboratory tests, the increasing relevance of appropriateness and patient safety issues, and new regulatory requirements for IVD users in the context of the IVDD provisions.

\section{External Quality Assessment Schemes}

The relevance of external quality assessment schemes (EQAS) and internal quality control in medical laboratories has since long been recognized by medical professional organizations in most European countries. In Central and Western Europe, EQAS covering a broad range of laboratory diagnostic parameters have therefore already been installed for decades in order to monitor the analytical performance of single laboratories. While initially performed on a voluntary basis, the participation in external quality assessment (EQA) programs was increasingly integrated into legal requirements for quality assurance programs during the last 10 years. In Germany, for example, the participation in EQA programs is mandatory by a regulation related to the Medical Device Act (Medizinproduktegesetz) [33].

The role of EQAS for post-marketing monitoring of IVD performance is recognized by European legislation: The IVDD points out the responsibility for medical practitioners like EQAS organizations to observe the performance of analytical systems in the European market and to inform the single laboratories, the manufacturers, and the competent health authorities about observed deficiencies. In this respect, the recently published harmonized standard EN 14136 sets requirements for EQAS organizations as far as the structure and organization of the programs, the assessment of the analytical data, and the consequences for the IVD vigilance monitoring are concerned [34].

\section{Accreditation versus Certification}

During the mid-1990s, the need for total quality management systems in medical laboratories initiated a controversial discussion on the kind and way of implementation of management systems and the fundamental documents that should be used. Since standards fitting the special requirements of medical laboratories were missing by this time, most European countries were in favor of accreditation or certification by adaptation of EN 45001 or EN ISO 9001 to the specific requirements of clinical laboratories. In 1994, only in the UK an accreditation system for medical laboratories was in operation. In Europe, accreditation according to EN 45001 started during the second half of the 1990s. However, during this initial period, specific accreditation requirements for the different fields of laboratory medicine were not always fully established. In Germany, for example, first accreditations by private accreditation bodies were performed in 1996, although substantial basics such as specific accreditation criteria for laboratory medicine or the definition of assessor competences were not completely defined yet. Along with the preparation of EN ISO 15189 as accreditation standard specific for medical laboratories, the implementation of quality systems with subsequent accreditation today seems the preferred procedure for most European medical laboratories. However, the situation remains heterogeneous as far as the accreditation standards and the quality systems themselves are concerned. In Austria, for example, certification according to EN ISO 9001 is currently the preferred procedure for implementation of quality systems in clinical laboratories [31]. In other countries, a considerable number of laboratories, especially in the private sector, is both accredited and certified, often due to economic and advertising reasons. Accreditation bodies within Europe currently mostly offer the accreditation according to both EN ISO 15189 and EN ISO/IEC 17025 on the basis of the customers', that means the laboratories' applications.

\section{Accreditation besides EN/ISO Standardization}

Apart from accreditation according to EN and ISO standards, accreditation procedures were established during the last years that refer to attestation of testing competence in specialized fields of laboratory diagnostics. In this context, the activities of the European Federation for Immunogenetics (EFI) include the accreditation of histocompatibility laboratories on the basis of yearly updated EFI standards for histocompatibility testing [35]. The standards are prepared in cooperation with the American Society for Histocompatibility and Immunogenetics (ASHI) and reflect the practices in European histocompatibility laboratories.

A number of European medical laboratories is accredited according to the standards of the College of American Pathologists (CAP) that performs accreditation in the USA and world-wide since more than 30 years [36]. Accreditation by CAP is based on standards that are translated into checklists and that usually do not refer to EN or ISO standards. The 
CAP accreditation system includes participation in the international inter-laboratory comparison program. Due to the special relevance of the standard, CAP most recently also offers accreditation according to EN ISO 15189.

\section{Quality Management Systems and Their Legal Status}

While the number of accredited medical laboratories in all European countries continuously has been increasing during the last 5 years, accreditation generally remained voluntary. In several countries like Austria, Belgium, Germany and Switzerland, however, it has been anchored in national legislation $[8$, 12, 31, 32]. In Germany, according to the Medical Device Act, accreditation by the designating authority ZLG is recognized as proof of competence according to the requirements of the New Approach directives [8]. Although accreditation is generally not mandatory, the requirement for implementation of quality management systems in medical laboratories has in the meantime been introduced into the national legislation of most Central and Western European countries [12, 31, 32]. In Germany, for example, requirements for quality management systems in medical laboratories are currently ahead of publication. They are closely related to the criteria of EN ISO 15189 and will be integrated - as it is already the case for the participation in EQA programs - into a regulation related to the Medical Device Act.

\section{Current Accreditation Practice and Perspectives}

Today, a considerable number of laboratories all over Europe is accredited on the basis of the standards EN ISO/IEC 17025 and/or EN ISO 15189. Given the fact that EN ISO 15189 was more recently published than EN ISO/IEC 17025 and that installation of accreditation systems according to new standards is time-consuming, it is not surprising that currently accreditation according to EN ISO/IEC 17025 is more abundant than according to EN ISO 15189 (fig. 5). In this aspect, only Germany and the UK, where the majority of laboratories have already been accredited according to EN ISO 15189, constitute an exception. In most other European countries, accreditation according to EN ISO 15189 started during the years 2004/05. In France, for example, the first accreditation according to EN ISO 15189 was even performed in 2006.

Since EN ISO 15189 is most appropriate for the implementation of quality management systems for routine diagnostic laboratories, the future activities of accreditation bodies, especially in the voluntary area, will probably focus on the accreditation based on EN ISO 15189. Routine diagnostic laboratories constitute the majority of accredited medical laboratories, as it is reflected by the total number of German accredited laboratories in the voluntary area in comparison with the number of laboratories accredited by the designating authority ZLG (fig. 5).

Of note, in the area subject to statutory regulation, where test-

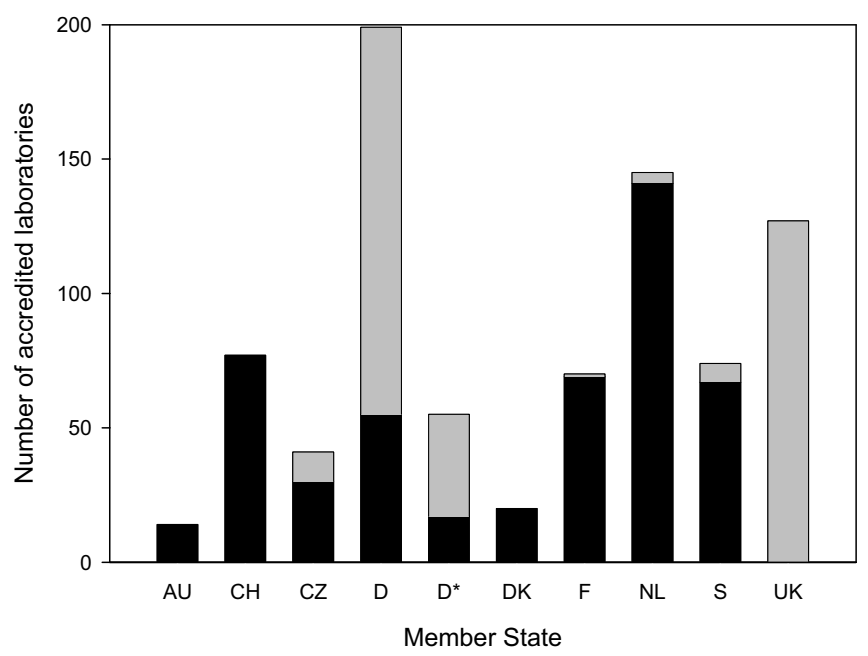

Fig. 5. Accreditation experience in Europe. Accreditation of medical laboratories in a number of European countries according to EN ISO 15189 (grey) and according to EN ISO /IEC 17025 (black) is shown. D* indicates the number of laboratories in Germany that are accredited within the scope of European New Approach directives, i.e. under the terms of the Council Directives 90/385/EEC, 93/42/EEC and/or 98/79/EC for clinical laboratory testing in the various fields of laboratory diagnostics. Data were obtained by search for accredited medical laboratories on the websites of the accreditation bodies in the different countries (by April 2006).

ing of medical devices including IVD is part of the conformity assessment activities of medical laboratories, accreditation according to EN ISO/IEC 17025 directly refers to physical device testing and evaluation in the scope of the IVDD. However, in most countries, the laboratory accreditation scopes as issued by the accreditation bodies do not adequately address the aspect whether accreditation according EN ISO/IEC 17025 is performed within the scope of New Approach directives and therefore considers the supplementary legal requirements or not. Although one may assume that this should be the case for accreditation performed by governmental accreditation systems, there is need for clear policies and adequate documentation of the accreditation scopes in this aspect. This might help to improve transparency of accreditation for the stakeholders of the medical devices system, especially for manufacturers and notified bodies involving medical laboratories for conformity assessment activities.

As far as the statutory context is concerned, future perspectives for accreditation of medical laboratories will mainly be influenced by the present development in the field of EU legislation. Firstly, the currently performed review of the medical devices directive 93/42/EEC intends to improve the pre-market clinical evaluation of medical devices and will therefore include the requirement for enhanced clinical testing of these products [37]. Europe's regulators recognized the need to improve the quality of clinical trials - a fact which might also have an impact on more precise quality requirements for medical laboratories involved as testing bodies. Secondly, new as- 
pects can be expected from the currently discussed Review of the New Approach. The Review plans, among others, to provide an explicit legal base for accreditation which shall be the last layer of control in the conformity assessment system [38]. In this context, it is planned to define more precisely the criteria for both designating authorities and notified bodies. The latter will also concern the accreditation criteria for laborato- ries in the context of the New Approach requirements. Furthermore, the restoration of presumption of conformity for European standards shall be addressed. Hopefully, the current activities in European legislation and standardization will further contribute to legal recognition of the key importance of medical laboratories for patient health and safety of the European medical devices system.

\section{References}

1 Directive 98/79/EC of the European Parliament and of the Council of 27 October 1998 on in vitro diagnostic medical devices. Official Journal of the European Commission L 331/1, 07/12/1998.

2 Council Resolution of 7 May 1985 on a new approach to technical harmonization and standards. Official Journal of the European Commission C 136, 04/06/1985.

3 Commission Communication to the Council of 15 June1989 on a Global Approach to certification and testing - quality measures for industrial products. Official Journal of the European Commission C 267, 19/10/1989.

4 Council Resolution of 21 December 1989 on a Global Approach to Conformity Assessment. Official Journal of the European Commission C 10, 16/01/1990.

5 93/465/EEC: Council Decision of 22 July 1993 concerning the modules for the various phases of the conformity assessment procedures and the rules for the affixing and use of the CE conformity marking, which are intended to be used in the technical harmonization directives. Official Journal of the European Commission L 220, 30/08/1993.

6 Council Directive 90/385/EEC of 20 June 1990 on the approximation of the laws of the Member States relating to active implantable medical devices. Official Journal of the European Commission L 189/17, 20/07/1990.

7 Council Directive 93/42/EEC of 14 June 1993 concerning medical devices. Official Journal of the European Commission L 169/1, 12/07/1993.

8 Gesetz über Medizinprodukte - MPG vom 2. August 1994 in der Neufassung vom 7. August 2002; BGBl I S. 3147.

9 EN 45003:1995: Calibration and testing laboratory accreditation system - General requirements for operation and recognition.

10 Guide to the implementation of directives based on the New Approach and the Global Approach. Office for Official Publications of the European Communities, 2000. http://europa.eu.int/comm/enterprise/newapproach/legislation/guide/document/ 1999_1282_en.pdf.

11 EN 45001:1995: General criteria for the operation of testing laboratories.

12 Edelhäuser R, Schoerner C, Weidemann G: Medizinisches Labor - Qualitätsmanagement und Akkreditierung. Stuttgart, Wissenschaftliche Verlagsgesellschaft, 2004.
13 Haeckel R, Kindler M: Effect of current and forthcoming European legislation and standardization on the setting of quality specifications by laboratories. Scand J Clin Lab Invest 1999;59:569-573.

14 ISO/CEN: Agreement on technical cooperation between ISO and CEN, (23.12.2002), Chapter 4. www.cenorm.be/boss/supmat/refdoc/archive/ms/msO 02.htm.

15 Ensthaler J, Funk M, Edelhäuser R, Schaub G-H: Accreditation of testing and certification bodies; published by the Commission for Occupational Health and Safety and Standardization (KAN) 2003. www.kan.de/pdf/bericht/eng/Beri30e.pdf.

16 EN ISO/IEC 17025:2005: General requirements for the competence of testing and calibration laboratories.

17 EN ISO/IEC 17011:2004: Conformity assessment general requirements for accreditation bodies accrediting conformity assessment bodies.

18 EN ISO/IEC 17000:2004: Conformity assessment vocabulary and general principles.

19 ISO/IEC Guide 25: General requirements for the competence of calibration and testing laboratories, 3rd ed, 1990.

20 EAL-Guide 25:1997: Accreditation for Medical Laboratories.

21 ISO 9001:2000: Quality management systems - requirements.

22 EN ISO 15189:2003: Medical laboratories - Particular requirements for quality and competence.

23 Jansen RT, Blaton V, Burnett D, Huisman W, Queralto JM, Zerah S, Allman B: Essential criteria for quality systems in medical laboratories. Eur J Clin Chem Clin Biochem 1997;35:121-122.

-24 Jansen RT, Blaton V, Burnett D, Huisman W, Queralto JM, Zerah S, Allman B: Additional essential criteria for quality systems of medical laboratories. European Community Confederation of Clinical Chemistry (EC4) Working Group on Harmonisation of Quality Systems and Accreditation. Clin Chem Lab Med 1998;36:249-252.

25 EN 45011:1998: General requirements for bodies operating product certification systems.

26 Meyer-Lüerßen D: In-vitro-Diagnostika; in Anhalt E, Dieners P (Hrsg): Handbuch des Medizinprodukterechts, Grundlagen und Praxis. München, C. H. Beck, 2003, pp 443-470.

27 2002/364/EC: Commission Decision of 7 May 2002 on common technical specifications for in vitro-diagnostic medical devices. Official Journal of the European Commission L 131, 16/05/2002.
28 EN 13612:2002: Performance evaluation of in vitro diagnostic medical devices.

29 Zentralstelle der Länder für Gesundheitsschutz bei Arzneimitteln und Medizinprodukten: Spezielle Akkreditierungsregeln. 2003. www.zlg.de/download/MP/210_AR01_SpezAkkRegelnLabor.pdf.

30 European Commission, DG Enterprise, Directorate $\mathrm{G}$, Unit 4: Guidelines on a medical devices. Evaluation of clinical data. A guide for manufacturers and notified bodies. MEDDEV 2.7.1, April 2003.

31 Schweiger CR: Quality management in Austria. J Lab Med 2004;28:85-90.

32 Hänseler E, Siegrist HP: Quality management in Swiss diagnostic laboratories. J Lab Med 2004;28: $77-84$.

33 Verordnung über das Errichten, Betreiben und Anwenden von Medizinprodukten - MPBetreibV in der Neufassung vom 21.08.2002; BGBI I S. 3397.

34 EN 14136:2004: Use of external quality assessment schemes in the assessment of the performance of in vitro diagnostic examination procedures.

35 Standards for Histocompatibility Testing, Version 5.4. Approved by the Standards and Quality Assurance Committee on 22 April, 2005, Approved by the EFI Executive Committee on 24 April, 2005 , Effective from 1st January 2006.

36 CAP College of American Pathologists - Laboratory Accreditation Program: Standards for Laboratory Accreditation, 1988; Laboratory Accreditation Manual 2006.

37 Ecker W: Die klinische Evaluierung als eines der Hauptzielgebiete der Revision der Richtlinie über Medizinprodukte RL 93/42/EWG. Medizinprodukte Journal 2005;12:114-117.

38 European Commission, Enterprise and Industry Directorate General: Note to the Senior Officials Group on Standardization and Conformity asessment policy. CERTIF 2005-16 Rev. 2: Elements for a horizontal legislative approach to technical harmonisation. SOGS N 529 EN, Version 0.2, 2006. http://66,249.93,104/search?q = cache:EqQ_8y yFwEJ:www.vmpa.de/neue_home/N529\%2520EN $\% 2520$ Rev_2\%2520with\%2520track\%2520changes. $p d f+N 529+$ Commission and $h l=d e$ and $g l=d e$ and $c t=\operatorname{clnk}$ and $c d=1$. 